\title{
Fronteras del deseo. Homosexualidad, sociabilidad y afecto en la ciudad de Buenos Aires $(1950-1983) *$
}

\section{Patricio Simonetto**}

\section{Resumen}

El siguiente artículo reconstruye los nexos entre la vida urbana y los modos de socialización homosexuales en la ciudad de Buenos Aires entre las décadas del 50'y el 80'. Con el análisis de fuentes escritas, entrevistas, obras literarias y la elaboración del mapa, se propone interrogarse sobre las características de esta subcultura. Entre los objetivos se destaca: la relación de la subcultura homosexual con otros grupos sociales como trabajadores o marginales, los modos de circulación y apropiación del espacio, las tácticas de resistencia a la violencia publica y las redes afectivas que pusieron en marcha. Procesos que son contextualizados en los cambios estructurales que vivió la ciudad a los largo del siglo XX.

La intención que impera en este texto es la de construir una narrativa endógena a la dinámica del grupo social para escapar a las descripciones que han catalogado este mundo como "secreto" o "invisible". Así también la de intentar disuadir la concepción de la identidad homosexual como apropiación de discursos producidos en otros campos como el médico o el estatal.

Palabras claves: Homosexualidad, Ciudad, Identidad Sexual, Fronteras.

" Enviado el 17 de mayo de 2015, aceptado el 4 de noviembre de 2016.

** Doctorando en Ciencias Sociales por la Universidad Nacional de Quilmes; miembro del Centro de Estudios en Historia, Cultura y Memoria (CEHCMe) y la Cátedra Libre de Género y Sexualidades. patriciosimonetto@gmail.com 
Frontiers of Desire. Homosexuality, Sociability and Affection in The City of Buenos Aires (1950-1983)

\begin{abstract}
This article reconstructs the connections between urban life and homosexual modes of socialization in Buenos Aires between 1950 - 1983. With the analysis of written sources, interviews, literary works and the mapping, we propose a description of this subculture. Among the objectives it highlighted: the relationship of homosexual subculture with other social groups such as workers or marginal people, modes of circulation and appropriation of space, the tactics of resistance to violence and emotional public networks launched. Processes that are contextualized in the structural changes experienced by the city to the twentieth century.

The intention that prevails in this text is to build an endogenous narrative of the social group dinamic to scape to the descriptions that cataloged this world as "secret" or "invisible". So also attempting to dissuade the concept of homosexual identity as appropriation of speeches made in other fields such as medical or state.
\end{abstract}

Keywords: Homosexuality, City, Sexual identity, Frontiers. 
Por las condiciones precarias en la que extendieron sus vidas, la historia de las disidencias sexuales es fragmentaria. Silenciada, ajustada, normalizada, resistente, en viejos o nuevos moldes, siempre se torna compleja de reconstruir. Lo azaroso de narrar biografías colectivas tensionadas entre la valoración y el agravio, la humillación y el orgullo; son desafíos para los cruces entre la perspectiva histórica y los estudios de género.

Vidas que no pareciesen tener un centro en su propia dinámica. En algunas narraciones los varones homosexuales aparecen como archipiélagos dispersos que se fueron bosquejando en las relaciones asimétricas con discursos y prácticas médicas, policiales o judiciales, entre otras. Este texto intenta profundizar en el sustrato histórico de algunos de estos varones, reconstruir sus margenes de agencia, para restituir cómo confeccionaron formas de sociabilidad afectivo-sexuales instituyentes de una identidad. Proceso que no fue autónomo, sino que renegoció sus límites e influyó también en la definición de las heterosexualidades dominantes.

La aplicación de los edictos policiales durante más de medio siglo (1932-1998) fue concéntrica en las vidas de las disidencias sexuales. La ambivalencia jurídica que penó la "oferta sexual" en la vía pública sometió a abusos policiales, chantajes, golpizas y apresamientos a homosexuales que deambulaban por la ciudad de Buenos Aires (D'Antonio, 2015). Este hecho no subsumió, ni fue menor para sus vidas. Mirar como socializaron, subjetivaron y se identificaron estos varones implica rastrear las tácticas que pusieron en juego para vulnerar espacios normativos y birlar controles, al fin, para efectuar su existencia. Observar el escenario de prácticas aparentemente discontinuas pero constituyentes de su concreción como grupo.

Nos referimos a homosexuales para dar cuenta de una forma de experiencia históricamente situada entre la expiración del siglo XIX y la apertura democrática del 83'. Diferenciable del modo de agenciamiento gay (Meccia, 2015). El recorte temporal entre 1950-1983 responde a la consideración de que a pesar de la alternancia entre gobiernos civiles y militares prevaleció la 
continuidad en las dificultades con las que se encontraron estos actores y las prácticas con las que lo sopesaron. También porque considero que en este periodo se condensaron procesos previos que dieron a estas formas de vida una nueva dinámica.

En este artículo discutimos algunos sentidos comunes historiográficos en los que prevalece la noción de "invisibilidad". El hecho de que los homosexuales tuvieran tácticas de acción, se nominaran así mismos como tales y reflexionaran al respecto, como también que fueran rechazados por otros, referencia a un grupo social con un grado prolifero de interconexión que desintegra la idea de imperceptibilidad. El secreto no fue un aspecto que tornó intangibles a los homosexuales para el resto social, sino que operó como un método con el que se negociaron (a veces con violencia) las fronteras presentadas como dicotómicas entre varones heterosexuales y homosexuales.

Los espacios comunes fueron esenciales en la reificación de estas fronteras. Por lo que las preguntas sobre el género y la dimensión son pertinentes para reconocer cómo lo material del paisaje afecta la relación entre los sujetos, pero también, cómo los discursos se materializan cuando por ejemplo agencian sexualmente estos sitios (Conlon, 2004). El análisis a escala reducida de los sujetos permite problematizar la masculinización de su soporte espacial y repensar su intersección entre género y clase (Zubia y López, 2015). Así, las nuevas preguntas que se realizaron a fuentes identificadas previamente sólo con las formas de asociación política homosexual de los setenta, como la indagación de las memorias de estos varones, ayudó a pensar la relación de sus vidas con el mundo urbano, como en el caso de Brasil (Braz, 2015) o México (Laguarda, 2010).

Este artículo cuenta con tres apartados. En el primero, describiré los cambios que atraviesan el periodo de recorte pero que configuran a la homosexualidad en relación a lo urbano, para contextualizar en este fenómeno la reconfiguración de estas formas de existencia disidentes y la presión que el Estado efectuó sobre ellas. En el segundo, analizaremos el sistema de "teteras" y los puntos de encuentro que los homosexuales confeccionaron en la 
ciudad, para ver de qué modo estos espacios eran agenciados en convivencia con otros mundos sociales. En tercer lugar, desplegaremos algunas de las tácticas expuestas por estos agentes para sobrevivir como grupos.

El corpus documental se sustenta en fuentes escritas y entrevistas utilizadas como fuentes primarias en mi investigación sobre el Frente de Liberación Homosexual - FLH (Simonetto, 2016). Al que se le agregaron nuevas entrevistas y materiales inéditos de elaboración propia.

\section{La ciudad: ambivalencia del "desorden"}

La incipiente visibilidad que adquirieron desde los 40s' los puntos de socialización homosexual (Acha, 2014) fue la expresión de la consolidación de la identificación común de un conjunto heterogéneo de prácticas eróticas, amparada por la urbanización generada por la expansión del capital entre el Siglo XIX y el XX. El motorizado advenimiento de una sociedad de masas y la cuota de anonimato que presentaba Buenos Aires posibilitaron nuevas formas de realización. Así, la homosexualidad moderna en cuanto suponía un modo de concebirse y circular en relación a otro dominante emergió como un imaginario urbano, un modo de imaginación limitada generalmente a este paisaje (Gorelik, 2002).

Aunque en las zonas rurales hubiese prácticas sexuales entre varones, las condiciones de posibilidad de la urbe permitieron la emergencia de un submundo social, ampliaron su autonomía relativa frente al control comunal y dispusieron una trama de experiencia común (Chouncey, 1994; Eribon, 2001). La formación de masas de trabajadores asalariados libres con sus tiempos muertos y formas de ocio abrieron la posibilidad a asociación entre experiencias eróticas y un modo de vida (D'Emilio, 2006).

El proceso dinámico de acumulación y estructuración de capital entre 1880-1930 fue el telón de fondo que alteró las posibles formas de relación entre géneros. La inserción en el mercado internacional como exportadores de materias primas, la modernización tecnológica mediante la importación de bienes 
manufacturados, la constitución de ciudades nodo y el desarrollo del transporte (trenes, rutas y subterráneos) que generó la movilización de mano de obra masculina; trastocaron la vida cotidiana urbana (Barrancos, 2006; Ben, 2014). Buenos Aires se transformó exponencialmente: entre 1880 y 1895 se formaron los primeros anillos del conurbano y el puerto atrajo jóvenes de ultramar con expectativas de progreso social en la Argentina. La crisis rural del 29' potenció el traslado masivo a los cordones del conurbano ensanchando la ciudad (Gorelik, 2004).

La vivaz movilidad horizontal de los pobladores modificó la relación social con el espacio y mermó viejas formas de restricción. Los solteros, en pareja, adultos o jóvenes abandonaron la tutela familiar en búsqueda de empleo formando otros modos de filiación afectiva. La prolongación de una diáspora ajena a los márgenes de la familia tradicional, como unidades productivoafectivas de control, y la conquista de autonomía financiera y tiempo libre, generó micro libertades para la experiencia. Estas ampliadas ciudades dispersaron las normas de control y templaron los códigos de género. Reafirmando que existe una relación entre patrones de acumulación, procesos demográficos y de modernización en la historicidad del género (Floyd, 2009). Proceso que se dinamizó en la segunda mitad del siglo $\mathrm{XX}$ con el movimiento del excedente rural a la industria alentado por el peronismo (Sidicaro, 2010).

Cuando hablamos de cuerpos que se desplazaron inferimos también su capacidad de transformarse a sí mismos y a las condiciones materiales que los rodean. Un cuerpo capaz de dotarse de lenguaje pero que con un sustrato material está obligado a asociarse y trabajar para sobrevivir (Eagleton, 2001). Estos cambios les brindaron facultades para que estos sujetos se enlazaran entre sí, socializaran, compilaran nuevas formas de existencia bajo nuevas nominaciones y praxis.

En paralelo al cambio del panorama urbano las crecientes ondas de "caos", la amenaza de las organizaciones "subversivas", la creciente sindicalización, y el cambio de mapa en la ciudad despertaron desde fines del siglo XIX "pánico" en las clases 
pudientes (Gorelick, 2004). Las ciudades condensaban para los homosexuales "refugiados" la mixtura entre la libertad del anonimato y la masividad, los riesgos de la represión y la violencia. Como producto de la sedimentación de los discursos conservadores desde 1932, los códigos de falta de la ciudad intercedieron en la sexuación del espacio restringiendo formas que escaparan al canon o hiriesen la "moral pública". Entre estas normativas ocupó el centro el edicto 2 " $\mathrm{H}$ " que peno la propuesta "carnal" en la vía pública, con la que se sanciono especialmente a homosexuales y prostitutas. Dispositivo normativo que empleo el Estado para intentar suplir controles anteriormente depositados en la sociedad civil ante la percepción del declive del imaginario de orden dominante. Las formas de represión estatal pueden inscribirse en este marco, como una reacción a fuertes cambios socio-culturales empujados por la fuerza centrífuga del capital. Medidas que fueron auxiliadas por el discurso médico positivista que identificó a homosexuales e invertidos con agentes patógenos antagónicos al desarrollo de la "nación" (Bao, 1993; Figari, 2012; Ramacciotti y Valobra, 2013; Salessi, 1995; Nesvig, 2001).

El discurso peronista modificó las relaciones de género en cuanto virilizó a la clase obrera frente a una oligarquía señalada como femenina. A su vez, continuaron las razzias como medio de punición a las sexualidades disidentes y afirmación del canon heterosexual. El peronismo fue en este ámbito paradoja porque mientras en el Estado permaneció la dinámica coactiva y androcéntrica, el proceso de modernización y acceso a nuevos derechos transformó materialmente el abanico de posibilidades estimulado el largo proceso señalado (Acha, 2014).

La censura y la represión a las conductas consideradas obscenas se extendieron en los años sesenta: limitándose en la ciudad el uso de minifaldas, los pantalones anchos y el pelo largo en los varones, los besos en las plazas y lugares públicos, la concurrencia a hoteles alojamiento, las salidas a boites y whiskerías. Manifestaciones restringidas por la fuerza policial (Fellitti, 2006). La campaña moralista iniciada por Onganía y continuada por los mandatos peronistas artículo la aplicación de 
edictos y razzias como un medio de dominio especifico en el campo moral. Los homosexuales podían ser detenidos hasta 30 días y ser llevados a la cárcel de Devoto, donde residía el pabellón 5 to "bis" reservado para "amorales" que, acusados de prostitución o corrupción de menores, eran sometidos a prácticas denigrantes y violentas (Somos, 1973, nº 1; Jauregui, 1987).

Las explicaciones sobre la represión a la homosexualidad se enmarcaron en interpretaciones del tipo moral, psíquico y sobre ellos se posaba el "fantasma" de amenazar la reproducción cuantitativa de la población. Según Fellitti (2006) en Argentina distintos gobiernos, civiles y militares, consideraron que el tamaño de la población constituía un importante factor geopolítico que no podía descuidarse. Este discurso, presente en el poblacionismo argentino desde mediados del siglo XIX, persistió y operó sobre las políticas de Estado de la primera mitad del siglo XX. A partir de la década del 60' las preocupaciones se complejizaron. Las recomendaciones internacionales asociaron el exceso de población con la pobreza e invitaron a los Estados a atender esta tarea (Biernat, 2007). Por consiguiente, la regulación o el fomento de la procreación de manera desigual para los distintos grupos sociales (favoreciendo la de los sectores medios y desestimulando la de los sectores menos favorecidos económicamente), interactuaron con la presencia de un fuerte componente moral arraigado en el Estado argentino y sus fuerzas armadas.

A pesar de que desde principios de la década del 50' la aparición de la juventud como un actor político crítico en la escena pública tendió a debilitar los cánones clásicos familiares y a establecer nuevos códigos de conducta en los modos de formación de la pareja, las desigualdades de género y la matriz heterosexual se mantuvieron. Este proceso fue heterogéneo entre las clases sociales y se extendió principalmente a los sectores medios, que aceptaron la iniciación sexual pre-marital de la mujer, entre otros cambios de pautas (Cosse, 2010: 11-23). En el año 1968 el régimen militar surgido de la llamada "Revolución Argentina", aprobó por decreto un nuevo código civil que le otorgaba mayores libertades civiles a las mujeres en el ámbito matrimonial, es decir, que 
mientras que por un lado constituía un avance en las legislaciones que asumieran los derechos civiles de varones y mujeres, tendía a fortalecer la institución del matrimonio y a la familia nuclear (Giordano, 2012:185-198).

Confirmado, revista fundada por Jacobo Timermann en 1965, dedicó un número a Luis Margaride. Allí era descrito como "un funcionario municipal, con atribuciones tácitamente limitadas". Una figura polémica era un funcionario policial que se ocupó de diseñar y dirigir estas políticas coactivas en vistas de sostener una concepción rígida de la "moral", una de sus principales características sería la de sostenerse en diversos cargos jerárquicos más allá de los cambios políticos. La investigación periodística se proponía confirmar y desmentir la acción del oficial que "en algunos casos se confirmaron y en otros demostraron que la fantasía popular corre más rápido que un huracán". Posteriormente Margaride sería nombrado como una de las máximas autoridades de la policía federal (1974) y reconocido por la izquierda como miembro activo de la Alianza Anticomunista Argentina (AAA).

Se enumeraban un conjunto de hechos que eran afirmados o desmentidos. Entre los confirmados se destacaba: la incautación de materiales pornográficos y prensa amarillista; la redada a un bar de intelectuales y artistas, donde la reconocida artista pop Martha Minujin, sería reprendida por un oficial de policía por su "flequillo largo"; la iluminación con refractores de "Villa Cariño", el lugar donde se reunían jóvenes en sus autos a tener relaciones sexuales, pedido de documentos y detenciones. La vedette Zulma Faid denunciaría haber recibido amenazas de la división de moralidad dirigida por el oficial. Para el diario, en general, eran pequeños excesos en el marco de un pedido "de más rigurosidad" a la hora de aplicar la ley. Se afirmaba que lo central de los controles solicitados buscaba garantizar que los jóvenes no fueran del mismo sexo. Aplicación de razzias, y que el resto eran exacerbaciones y rumores populares más que hechos. Lo cierto es que el intendente Eugenio Schettini denegó al funcionario su 
derecho a dar declaraciones públicas y desmintió que se reglamentaran el toque de queda y la prohibición de faldas.

La detención era sin duda una amenaza poco sutil que regulaba los imaginarios sociales de los homosexuales, pero en el cual no se agotaron ni sus experiencias ni sus modos de existencia. En un documento llamado Análisis de la represión policial y el comportamiento homosexual frente a la misma (s/f), el Frente de Liberación Homosexual, un colectivo heterogéneo cuya propuesta consistió en intentar aunar el ideario de la revolución social y una revolución sexual, relataba la experiencia de la detención en la cárcel de Devoto. Eran detenidos en el pabellón quinto bis donde sufrían hostigamiento de guardias y presos. El castigo por excelencia para los homosexuales era el divertimento de sus compañeros. En sus propias palabras: "¿Qué son dichos divertimentos? Los guardias eligen a los presos heterosexuales (?) más desesperados sexualmente y que a su vez desprecien más a los homosexuales, formando con ellos, grupos de 15 o 20 individuos en celdas... a donde echan a uno o dos homosexuales. Fácil es imaginar la verdadera carnicería de desesperación y deseo que se desarrolla (...) en donde ya no entra en juego la seducción sino el valerse de la fuerza bruta. Además se establecen premios al que haga gritar más (de placer dicen los guardias) a las víctimas." (Simonetto, 2016).

En síntesis, podemos marcar dos procesos distintivos en los que se inscriben estas prácticas. Primero, las transformaciones materiales que ampliaron el marco de posibilidades y fueron decisivos en la formación de la identidad homosexual moderna. Segundo, la composición de mallas de represión estatal, que aunque no explica la totalidad de la vida homosexual, fue un elemento distintivo con el que debieron lidiar.

\section{El sistema de teteras}

Los homosexuales llamaron teteras a espacios públicos utilizados para el encuentro sexual contingente entre varones. Difundidos por vía oral su localización formó parte de un 
conocimiento comunitario necesario para entablar contactos sexuales endógenos y exógenos. Su reconstrucción permite ver, más allá de la oposición política a la coerción estatal del FLH y el feminismo, cuales fueron las estrategias de los débiles, los quehaceres cotidianos, con los que homosexuales sortearon las presiones dominantes (Scott, 1985).

Buenos Aires, como todo espacio, no fue estático ni vacío. Entendemos la superficie no solo como producto de la interacción de las fuerzas sociales de producción sino que reconocemos su capacidad fructuosa: en cuanto actúa como soporte de las relaciones sociales es concomitancia social (Lefebvre, 1991). En la década del 30': se consolidó el centro de Buenos Aires por sobre su periferia. Mientras que la intervención de las políticas públicas en materia urbana se cimentó sobre la premisa de la privacidad "familiar", hubo una exponencial transformación de los usos del espacio público para el esparcimiento por parte de los trabajadores y los sectores populares (Ballent, 2009:41-48).

Ser homosexual implicaba un relativo conocimiento sobre un complejo mapa de teteras que incluía baños, cines, estaciones de subte o tren, y zonas de caminata. ${ }^{1}$ Saberes compartidos y necesarios para concretar encuentros sexuales (Raspisadi; Morandelli, 2001). Territorios que estaban cargados de numerosas nominaciones, lo que resaltaba que allí se yuxtaponían la existencia y tránsito de diversos grupos e identidades. Esta cohabitación afirma que la sociabilidad homosexual no se cerró en sí como una entidad autónoma. Los varones se movieron entre fronteras que delimitaron lo expectable para su mundo y que los relacionaron con un complejo urdimbre de orbes sociales urbanos, que hacinados en un mismo espacio, concatenaron relaciones de género y clase. Para materializar estas coordenadas elaboramos

1 Mientras que en Argentina los homosexuales recurrieron a espacios no convencionales para establecer formas de socialización sofocados por los controles público, en las ciudades brasileras, primó el encuentro en espacios como bares y saunas (Braz, 2015). En la ciudad de México existió también ciertas zonas llamadas "rosas" donde primó el encuentro y "ligue" entre homosexuales (Laguarda, 2010). 
dos mapas utilizando referencias de entrevistas y fuentes escritas del periodo. Estos materiales escenifican ese saber no estático, cambiante y fragmentario, que se ubicó en el corazón de la existencia homosexual masculina pero al que también apelaron otros actores (como ejemplificaremos los chongos).

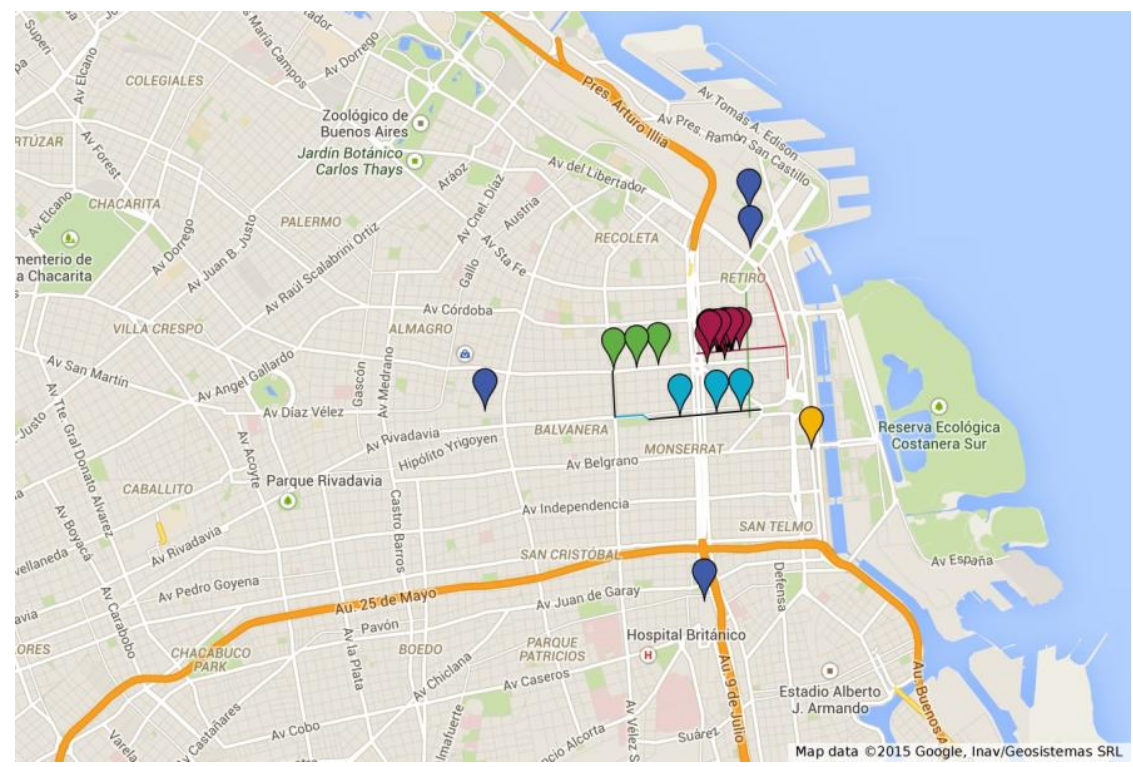

Mapa 1. Elaboración propia en base a entrevistas y consulta de la publicación Somos.

Los recorridos eran céntricos y periféricos, fijos y móviles. Registrarlos era parte de un sistema de codificación/decodificación dinámico que expresaba una cultura homosexual enérgica. Los baños de las estaciones del conurbanos aparecen en los extremos norte, sur y este. En amarillo el puerto y sus alrededores. En celeste y en violeta los cines de la calle Lavalle y de Avenida de Mayo. En verde se marcan algunas de las confiterías. En un verde más claro se delimita la calle Florida y sus llamados café "al paso" a lo cual se le suma el camino del "bajo" (Leandro Alem). Sitios que con características diferenciables bosquejaron las fronteras 
imaginarias que estos espacios conjugaron entre grupos sociales. Lo cual no significa que en los anillos del conurbano y en los barrios periféricos estas redes de "teteras" se extinguieran. Néstor Latrónico (25/4/2015), un joven del conurbano bonaerense dactilógrafo que viajaría más tarde a Nueva York para escapar de una Argentina asediada para los homosexuales, recuerda que en Avellaneda los cines "Roca" y "Colonial" también fueron sitios de encuentro. En 1973 en Lanús se abrió el boliche Monalí, aunque tuvo que cerrar poco tiempo después tras una balacera.

Entre las teteras los baños públicos contaron con cierta popularidad. Tener sexo en ellos fue un modo de apropiación del espacio que medió entre las nociones de lo público y lo privado problematizando su suposición dicotómica. Eran el fetiche de una libertad privada sitiada, el artista plástico Roberto Plate, participe en el movimiento contracultural que rechazó las estrictas censuras del dictador Juan Carlos Onganía (1966-1970), montó un baño público donde en el resguardo de la intimidad los asistentes podrían hacer un descargo emocional. Los graffitis pintados en su interior contra el gobierno llevaron a la clausura policial del espacio por considerar que afectaba la moralidad pública. El artista tomó la barra de clausura y la presencia policial como parte del espectáculo. En Colombia Miguel Ángel Rojas desarrollo un teatro testimonial de la vida homosexual con sanitarios como escenografía. Con una actitud voyeurista pretendió visibilizar con fotografías la actividad homosexual en los tocadores. En 1972 Álvaro Barrios retomó imágenes homo eróticas de grabados clásicos y, en 1975, Carlos Leppe, artista vanguardista del grupo Escena de Avanzada, hacía instalaciones donde ponía el cuerpo como construcción social en tensión con un sistema de secuencias gráficas (AA.VV, 2013).

Los aseos de estaciones de trenes o de confiterías fueron intersecciones entre la hostilidad pública y la soledad del mundo privado. El desplazamiento y esparcimiento en las teteras era un devenir por los márgenes del "ambiente" homosexual, una zona de frontera que mostraba porosidad, un carácter endeble que permitía pactar relaciones entre grupos. "Los baños públicos son 
nuestros salones de fiestas" - escribiría algún anónimo en Somos, la publicación del FLH. Allí argumentaría que aunque para la mayoría eran considerados "sucios" y aberrantes, para los homosexuales eran los centros del deseo descarnado, del encuentro sexual con extraño y se pregunta "Si los católicos se reunían entre cadáveres ipor qué nos daría vergüenza a los homosexuales hacerlo entre pis y caca?” (Somos, n³, 1973). Para uno de nuestros entrevistados asistir a esos baños era como "acudir a misa". Allí se entrenaban en el arte de "mirar", de evaluar el cuerpo del otro y sus gestos para lograr aproximarse (Latrónico, 25/4/2015). Los sortilegios de la mirada, la manipulación del posicionamiento de los ojos, erigían un metalenguaje compartido.

Las estaciones Constitución (sur), Retiro (norte) y Sarmiento (este) eran lugares predilectos, eran elegidas por su permeabilidad. Ubicados en los márgenes de la ciudad, eran signo de la flexibilidad de los homosexuales, como todo sitio de tránsito, contactaban con variados actores. La búsqueda del ligue los llevaba también al cuerpo laborioso de los trabajadores de las periferias urbanas (chongos). Como se relató en La narración de una historia (1953), donde un joven estudiante pacta con la mirada un futuro encuentro sexual en el edificio de Constitución. De allí se dirigen a un descampado en la zona norte del conurbano donde se masturban mutuamente. En sus diálogos relatan lo filtrable de la zona portuaria donde se podría tener relaciones con marineros, estibadores, jóvenes migrantes $y$ "lumpenes" de la zona.

Estas fronteras sexuales agujereadas permitían que en el sexo entre varones participasen hombres con identidades homosexuales o heterosexuales. Para los varones de clase media estos sitios eran pasajes entre el mundo heterosexual representado como aquello exótico, antagónico e inalcanzable y un mundo homosexual cargado por epítetos negativos, desposeídos de capital simbólico para poner en juego. Al igual que el morocho del relato citado, los trabajadores y jóvenes de barrios populares atraían a varones que asumían una identidad homosexual 
"plena". Los bordes de estaciones y puertos estaban atestados de bares propicios para la sociabilidad obrera entre varones (Schneider, 2005:357-370).

Lo indefinido deja abierto el abanico de posibilidades que se presentaban. Como describió el escritor polaco Witold Gombrowicz (2004) quien en una fiesta conoció a Gonzalo, el "puto", un millonario que se vestía con ropas de la prole para buscar por la ciudad jóvenes aprendices, obreros o camareros. Recorría el barrio portuario para encontrar marineros que eran su "deleite". Estas zonas fronterizas eran riesgosas, Gonzalo resultaba violentado en muchas ocasiones. Podía ser víctima de una violencia insospechada o ser robado por algún "chongo".

Los baños de las confiterías también fueron pasos fronterizos. El color verde en el mapa señalan a "El foro" (Corrientes 1399) y "La paz" (Corrientes 1593). En ellos coexistieron jóvenes de capas medias. La aparición de las juventudes en la escena social, los jóvenes rockeros, los estudiantes universitarios (que entre 1930 y 1975 habían pasado de 10 mil a 200 mil), las jóvenes solitarias que se desprendían del control hogareño y recorrían también esta ciudad en grupo de amigas, en charlas, bares $\mathrm{y}$ en los cines estableciendo diálogos y seguramente cruzados con este mundo homosexual (Manzano, 2014). El FLH, en los diálogos entablados con otros actores de la izquierda dibujaron una triada de imágenes donde demostraban que los mismos baños que ellos relegaban al goce callejero eran espacios usados por organizaciones políticas, montoneros y trotskistas, y por jóvenes feministas, como espacios de intercambio de materiales y discusión ante el creciente clima represivo que se cernía sobre ellos. Es decir, que una variable distinta de la acción del Estado que obligaba a disponer a estos actores de los baños como nodos de intercambio y organización, obligaba a muchos jóvenes homosexuales a usarlos como bastidores de sus encuentros (Simonetto, 2016).

Trabajadores, pobres urbanos o jóvenes curiosos participaron de estos pasajes contingentes alentados por el anonimato de las urbes como actores híbridos. Dotados de 
saberes y códigos traspasaban las circunferencias de grupos y los valían a su favor. Estos elementos eran un condimento del mundo homosexual que por un lado aportaba placer, deseo y goce, mientras que por otro lado incurría a nuevos peligros: taxiboys, policías de civil y otros actores que muchas veces los sometían al chantaje o la violencia (Anabitarte, Clarín, 9-2-2013).

Esta hibridez posibilitó la figuración del "chongo". Término que impregnó las narrativas homosexuales e invadió los relatos personales en las páginas de Somos (Simonetto, 2016; Insausti, 2012). Aunque su acepción original remitía a operarios aprendices, para los homosexuales denotaba varones masculinos que se reivindicaban heterosexuales (Sebrelli, 1964:83). La capacidad flexible del habitus lingüístico de la comunidad homosexual le permitió virar sentidos de términos confeccionados en otras latitudes sociales. También términos como homosexual, activo o pasivo, migraron de la psiquiatría decimonónica a las alocuciones de estos grupos. Así podemos pensar en qué medida la vitalidad de un grupo se explica en su capacidad de desprenderse de conceptos acuñados en otras comunidades o reapropiárselos. Por ejemplo, la transición de la auto nominación de homosexual a gay plantea la tensión dialéctica entre por un lado una cierta incapacidad de desligarse del discurso cientificista, pero también, de construir una identidad no dependiente de los conceptos emanados por las comunidades gay del centro occidental angloparlante.

Para Sebrelli (1964:83) los chongos estaban cargados de una masculinidad viril emanada por su procedencia popular, por lo que solían ocupar el rol de penetradores en el coito. Su participación en calidad heterosexual entre varones se explicaba por la maleabilidad de la moral obrera opuesta a la de la "pequeña burguesía" que maximizaba los idearios de las clases dominantes. Para el autor masculinidad y feminidad eran atributos clasistas. En el relato de Sebrelli la masculinidad y feminidad están atravesadas por la clase. El autor veía en las clases medias ("pequeño burguesía"), categoría compleja de análisis que responde a una formación metafórica de articulación de procesos 
político-discursivos (Adamovsky, 2013), un arraigo moralista sin relación con el mundo obrero. Su percepción brinda indicios explicativos en cuanto como explicó Norbert Elias las expectativas de pertenencia de los grupos medios a las clases dominantes, y su atención ante el miedo por la pérdida de estatus por los sectores bajos los forzó a articular fuertes procesos de coacción y contención hacia su interior. En el que la "moral" jugó como un elemento de distinción frente al resto.

Algunos homosexuales "pequeño burgueses" intentaban rehuir a facciones de clase que asociaban con la opresión de sus familias. Movilizaron un imaginario sobre las ilaciones asfixiantes de mesura interior de sus grupos como un modo de diferenciación frente a la "chusma". Quizás por esto la proyección de su deseo posará sobre agentes "externos" y promulgará estas tácticas de pasaje. Era también la carga de una prolífera cultura de izquierda que atravesaba lo social la que fustigaba a la "pequeña burguesía" frente a los trabajadores y los pobres urbanos, que representaban, la identidad del "pueblo" (Altamirano, 2011).

$\mathrm{El}$ "chongo" era la figura de encuentro con otros mundos. El viaje exótico y etnográfico hacia otras experiencias de placer (Sebrelli, Pagina 12, 27/12/2009). Era también la metáfora de escape a una pertenencia de clase en la que estos sujetos se imaginaron obturados. A su vez funcionó como escape al "ambiente homosexual", que era relatado como un sitio que imposibilitaba la creación de relaciones nuevas. Las teteras eran reivindicadas como zonas de intercambio con otros grupos que evitaban la reclusión en un guetto (Somos, n5, 1974).

La masividad y el anonimato urbano posibilitaron nuevas formas de administración de la información y la identidad. Aunque esto amortiguó riesgos, los actos sexuales en lo público no fueron fortuitos ni libres de perturbación. En Somos (n³, 1973) escribían que "El riesgo de asumir una relación amorosa con otro varón es el de perder tu trabajo, tus amistades y a tu familia". Probabilidades diversas entre la capacidad de controlar la representación propia ante la mirada del otro y el riesgo físico. 
La hibridez del "chongo" le permitía enlazar prácticas discursivas sustentadas en el estatuto de masculinidad. El acto sexual con otros varón se legitimaba en una libido incontrolable que lo obligaba, por necesidad monetaria o "calentura", a penetrar a otro pasivo (mujer o varón). Esto amparaba inclusive el sometimiento violento de un homosexual pasivo como medio de autoafirmación (Insausti, 2012).

La alianza con chongos podía modular lazos afectivos aunque con dificultades. La relación entre un joven con "Pedro", un vinero de un barrio de gran Buenos Aires, fracasaría por las exaltaciones masculinitas. Andaban juntos en un carro y él lo llamaba "mi señora". El narrador abandona la relación tras ser golpeado por no actuar como "su mujer" (Somos, no 3, 1973). En Revolver de Carlos Correa un empleado bancario delira con asesinar a un muchacho por miedo a que este revele sus encuentros sexuales. La presión por sostener su pertenencia a la comunidad imaginaria de varones, un lazo precario siempre al borde de perderse, fagocita al sujeto y lo impulsa al acto. ${ }^{2}$

Los pasajes sexuales se hicieron trasvasados por patrones de género que regularon las alianzas entre los actores y donde la condición de penetrador funcionó como garantía de una posición dominante. Para garantizar un apego menor a una cultura homosexual injuriada, los sujetos hibridos desarrollaron formas de administrar su "secreto" en el que la violencia fue la potencialidad extrema. El uso de la discreción fue un acto individual que limitó la capacidad de coacción del estatuto de masculinidad ante la mirada de los otros (Pecheny, 2002)

\footnotetext{
2 La relación entre violencia y masculinidad ha sido objeto de trabajo para una historiografía preocupada por la construcción dicotómica del binario homosexual/heterosexual. Ejemplos de esto son el estudio del asesinato de un turista a manos de un taxista brasilero a mediados del siglo XX (Rolim; Rodriguez, 2013) y la excarcelación de un ciudadano argentino que tras asesinar a un varón menor se lo eximió por considerar que este lo hizo para "ser un hombre completo" (Simonetto, 2015).
} 


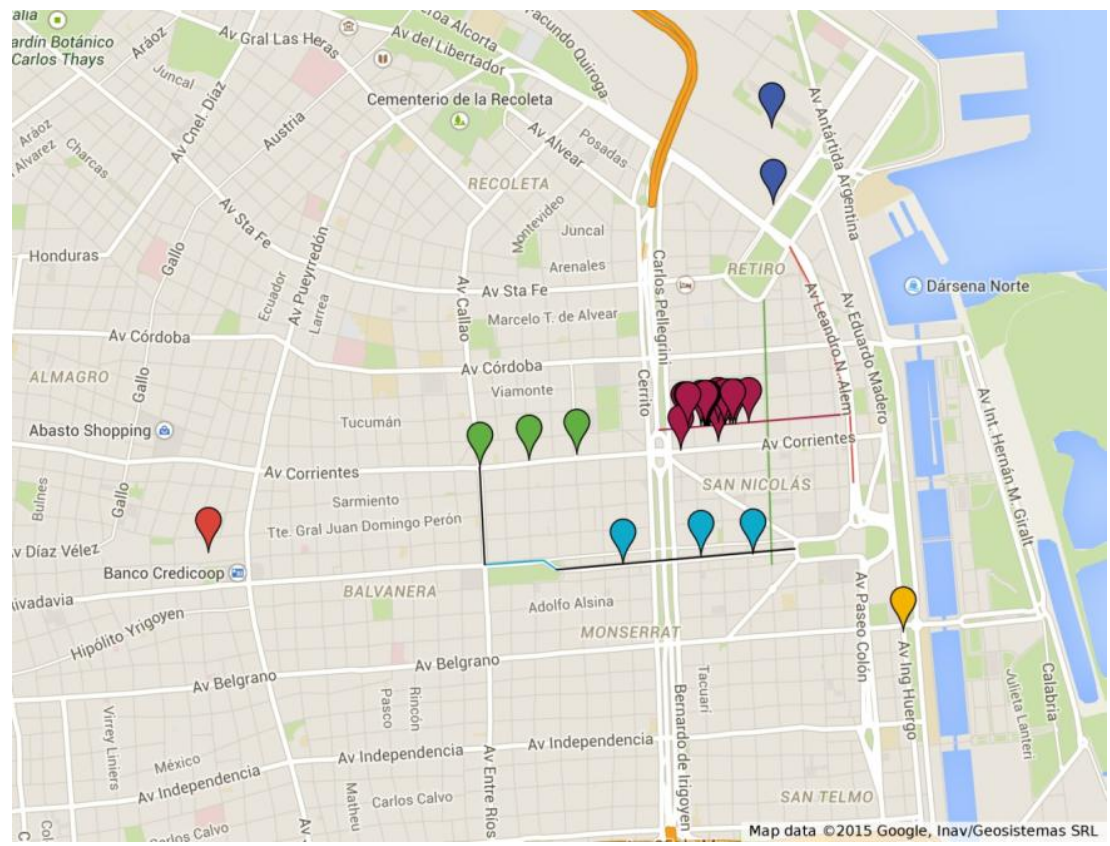

Mapa 2. Elaboración propia en base a entrevistas y consulta de la publicación Somos.

Al sistema de teteras ubicadas en las tangentes de la ciudad se le agregaban otros espacios céntricos, zonas de ligue que contaban con fluidez e intensidad. En el centro de Buenos Aires existían recorridos que permitían nexos eróticos. Los cafés prolongados por la calle Florida permitían la compra de preservativos en máquinas expendedoras. Desde Callao y Corrientes a la calle Rivadavia el recorrido de ligue es recordado como "intenso" (Néstor Latrónico, 24/4/2015). En la jerga se lo conocía como la zona de "saldos y retazos" asociando que allí iban los que no habían conseguido "nada". El "bajo" de Leandro Alem también era elegido, allí transitaba gente a la espera de colectivos o trasportes en viaje a la provincia. Los trasportes eran lugares de roce y miradas. Néstor Latrónico (24/4/2015) recuerda que el contacto llegaba a prominentes erecciones cuasi masturbadoras. 
Las conexiones del recorrido de Lavalle y de Avenida de Mayo acopaban las salas cinematográficas. Los cines, sobre todo en Lavalle, eran "teteras" masivas donde la oscuridad de las salas, la arquitectura, las columnas y butacas permitían el contacto físico entre varones. Estos eran: Luxor: Lavalle 669, Arizona (luego Cineplex): Lavalle 727, Ocean: Lavalle 739, Rose Marie: Lavalle 750, París: Lavalle 769, Ambassador: Lavalle 777, Monumental: Lavalle 780, Trocadero: Lavalle 820, Electric: Lavalle 836, Paramount: Lavalle 843, Hindú (luego Alfa): Lavalle 846, Sarmiento: Lavalle 852, Normandie: Lavalle 855, Metropol (luego Atlas): Lavalle 869, Renacimiento (luego Concorde): Lavalle 925, Select Lavalle: Lavalle 926 e Iguazú: Lavalle 940.

El cine Mundial era llamativo por su estructura de columnas que otorgaban privacidad a los concurrentes. Según recuerda Latrónico era de uso popular la frase "iAnda a pararte al Mundial!" que significaba "sos puto" (24/4/2015). Acto que desintegraba una noción de la cultura homosexual como recóndita y la restituye en un elemento de la trama porteña. Su verbalización como rechazo era un punto de contacto entre mundos sociales.

En síntesis, este apartado es una contribución al estudio de los códigos espaciales y la socialización homosexual de mediados del siglo XX. Los modos del sentir homosexual fueron flexibles, habilitaron interconexiones con otros, como una práctica consciente de encuentro que implicaba ciertas destrezas. Así también, el registro de la cultura homosexual por otros actores como policías, trabajadores, "chongos" y taxiboys permite marizar las teorías que describen nuestro objeto como mudo o silente (Chouncey, 1994; Fernandez, 2013).

\section{Tácticas de los débiles: miradas, encuentros y amistades}

En el apartado anterior hemos analizado una dimensión de la constitución del grupo, de acción en relación a la confección de códigos comunes de la comunidad homosexual, en concordancia a las capacidades exógenas de vinculación y circulación con otros grupos. En este apartado analizaremos algunas de las tácticas 
endógenas, aquellas tácticas de los actores débiles para tramarse entre sí.

Toda migración, en este caso metafórica, implica el armado de redes. Los homosexuales se valieron de grupos de amigos para instalarse y moverse por la metrópoli. Eran núcleos de socialización, comunidad de "locas", injuriados y expulsados que permitían la reconversión alternativa de una identidad connotada negativa en los núcleos primarios de socialización, familia, en una forma de vida positiva y viable.

Eran tejidos facilitadores que hacían potable sus formas de existencia interconectando búsquedas laborales, esparcimiento, ocio o formación de parejas. Una urdimbre en la que asentaron por la que se transmitían los saberes comunitarios, como la localización de "teteras", y se contenía a sus miembros. Experiencias como la del FLH quizás sean incomprensibles sin colocar dentro de los factores los lazos afectivos que se ponían en la construcción política (Simonetto, 2016).

Las situaciones extremas debelaban las lógicas de estas redes afectivas. El artículo "Sobre el asesinato de porota" relataba el asesinato de Ramón Callejos (escenificado con un mote femenino, Porota) a manos de unos "chongos". Esta enunciación materializa un arquetipo de los pactos de las zambullidas fuera de la comunidad. Porota (Ramón) fue golpeada y violada por un varón con el que sostuvo acceso carnal (Somos, n³, 1973). En 1970 en los diarios aparecían las referencias a muertes de homosexuales como "amorales" que alcanzaron 50 casos (Insausti, 2012).

La apelación a la nominación femenina, "la loca", remite a un código compartido entre "amigas". Una valorización de lo femenino, asociada al rol de penetrada, contrastaba con la masculinidad del asesino: "El chongo se la fifa y acaba. Le parte una botella en la cabeza, la atan y le ponen una mordaza". Luego relata la aparición en el diario. Lo que pone en juego este texto no es sólo el lenguaje de nominación femenina como un modo de identificación entre aquellos a los que está dirigida esta nota, otros actores implicados en redes similares, varones que reivindicaban 
su performance femenina. Las percepciones de una comunidad sexual, modos de establecer nexos y extenderse, en la búsqueda de sobrevivir en el tiempo (D'Emilio, 1998). Palabras que permiten ver la construcción de la dicotomía heterosexual/homosexual desde la posición subordinada, desde la creación positiva de su mismidad, más allá de las demarcaciones ejercidas desde la posición dominante.

La camaradería entre pares afirmaba el lugar imaginario en el que estos sujetos se inscribían. Un espacio denso en el que se tensionaban el lugar que los discursos sociales dominantes le otorgan al sujeto y los medios con el que este lo acepta o rechaza (Butler, 2003). La revista Somos fue un vehículo pensado para grupos políticos pero también para estas redes afectivas. Con humor dispersaba una lista con que enunciar los actos sexuales. Una suerte de diccionario que permitía la traducción entre los códigos exógenos y endógenos del grupo.

Estos relatos son documentos fortuitos para pensar cómo se hilvanaban las prácticas en el discurso homosexual, ver la forma en que estos se imaginaban a sí mismos. La femineidad enarbolada a contrasentido de la hegemonía masculina era un rechazo a la cultura oficial que suprimía sus vidas. Los relatos de Somos alentaron estas narraciones. "Hoy me siento muy cuarentona" ( $\left.n^{\circ} 5,1974\right)$ rezaba uno de ellos al relatar un encuentro erótico con un "chongo" que la "rozaría" por detrás como si fuese mujer. El uso del código femenino era oscilante. Aunque generalmente era sumisa $e$ inactiva también apelaba a un contrasentido de lo socialmente concebido como "femenino". En el artículo "un homosexual es aquel que no puede" un joven expresó su rechazó a una relación con un chongo porque este lo trataba como "su noviecita": le pagaba lo que consumía, socializaba con el bajo los códigos caballerescos y lo asumía como un ser "desprotegido". En sus palabras el autor desarmaba la noción pasiva de lo femenino escapando al carácter binario de las relaciones afectivas (Simonetto, 2016). Lo que muestra que los homosexuales no constituyeron un grupo hermético ni homogéneo, sino una cultura diversa, lo que nos debería invitar a 
pensar en homosexualidades como plural más que como sujeto univoco.

Además de funcionar como canales de transmisión, las redes de sociabilidad permitían poner en funcionamientos prácticas frente a la represión. El "minuto" fue un dispositivo compartidos por grupos políticos y disidentes sexuales para huir a las intimidaciones policiales. Néstor Latrónico (10-12-2013) y Sara Torres (12-12-2013), quién por aquel entonces emprendía sus primeros pasos en el activismo feminista, lo narran como un empleo táctico con el que se evitaban los peligros de los que eran víctimas tanto por su actividad política como por la condición de homosexual del primero. Los sujetos participantes de algún encuentro pactaban una coartada común. ¿Cómo? ¿Cuándo? ¿Dónde? ¿Por qué? Si alguna fuerza de seguridad los detenía, eran separados y estaban listos para mantener un mismo relato. Eran estas formas de engaños las que extendían charlas o encuentros de placer para evitar el control estatal. Estos eran parte de los micro saberes elaborados frente a una experiencia común, en la que por ejemplo, los homosexuales solían vivir el chantaje de policías que simulaban buscar encuentros en la teteras para luego quitarles dinero.

En la novela La otra Mejilla (1986) de Oscar Hermes Villordo un grupo de homosexuales en la década del 70' se reúnen en un bar para escapar de las razzias que acechan Buenos Aires. Cuando el protagonista y el acompañante presienten inminente la detención policial resuelven en unos minutos la respuesta de trayectorias comunes para disuadir la autoridad.

La apariencia física jugaba un rol en la mirada del agente de control. La represión no era equitativa y estaba teñida por una connotación de clase. En palabras del propio Latrónico (10-122013) "La cuestión de clase acá siempre fue patética." La vestimenta, los modos de hablar y la gestualidad, la "finura", constituían un signo que los tornaba impermeables a las sanciones de un régimen moralista. Mientras Néstor Latrónico viajaba a New York huyendo de un país asfixiante para los homosexuales, conocía a otros que disfrutaban de las mejores fiestas de la alta 
sociedad. Los miembros de la elite criolla no frecuentaban los baños ni las confiterías en busca de un encuentro, el ligue no se llevaba a cabo en colectivos en los que nunca habrían viajado. El régimen castrense constituyó una densa trama de normas y penalidades desigual entre las clases. La represión se concentraba entre aquellos sujetos que no podían portar "una buena chomba y unos zapatos bien puestos".

Y como destacamos, estas redes afectivas y de sociabilidad, tenían como característica actuar como grupos de contención. Sergio Pérez Alvares, quien también participó en el Frente de Liberación Homosexual, recuerda que su casa funcionaba como "refugio" y "asilo" para todos los expulsados por sus familias. De este modo estas redes tendían a construir caminos alternativos, mallas de contención, que unificaban y tramaban sentidos comunes en la composición del grupo.

\section{Conclusiones}

En este artículo nos interrogamos sobre cómo homosexuales de mediados de siglo en Buenos Aires sociabilizaron $y$ entretejieron una cultura común frente a experiencias relativamente similares. El cómo gestionaron sus formas de existencia propone abonar a una historiografía que piense a estas configuraciones subjetivas más que como emanaciones de la violencia estatal; restituyendo los canales mohosos y plurales que mediaron en la concreción de sus configuraciones subjetivas.

En primer lugar, la definición de que los cambios sociodemográficos, la disposición del tiempo libre y la movilidad de los "cuerpos" en la formación de la ciudades es un dato que no debe ser soslayado en la inspección de estos tópicos. De este modo, intentamos abonar a la hipótesis de que muchas de estas tácticas de resistencia, modos de sociabilidad y de encuentro hubieran sido impensables sin la transformación y agenciamiento de este espacio. Por lo cual sostenemos que la homosexualidad como categoría que responde a la capacidad de establecer nexos y redes comunitarios entre prácticas sexuales-culturales conexas no 
hubiese alcanzado la extensión y sofisticación sin los cambios abruptos de largo plazo que alteraron la ciudad de Buenos Aires. Atendiendo este contexto, sostenemos que la emergencia de los dispositivos normativos de control del espacio público iniciado en la década del 30', condensaron los miedos y expectativas de los grupos dominantes ante el "desorden" social que estos cambios colocaron en el centro, entre los que se encontraba la homosexualidad. La creciente aplicación de estos edictos por la represión de estos grupos se condice con el reconocimiento cada vez mayor del universo homosexual.

En segundo lugar, la descripción del sistema de "teteras", la materialización de un mapa que circulaba en el imaginario de este mundo y que lo construía en continuo, que sedimentaba nuevos espacios "conquistados" por los homosexuales varones, actúa como matiz al "mito de la invisibilidad". Como lo destaca Maximiliano Fernandez (2013) gran parte de los autores que han trabajado estos temas sostienen que en el período previo a 1980 las experiencias de varones homosexuales estuvieron marcadas por el "silencio" y la reclusión a la esfera privada. Pero este enfoque, el de reconocer a estas prácticas dispersas como parte de un sistema bastante aceptado, permite cuestionar en qué medida operaba este silencio. Al igual que la existencia de personajes "híbridos", de pasajes entre un mundo y otro, y hasta el reconocimiento (por vías coercitivas) de la existencia de este mundo por agentes estatales o civiles, debe ayudarnos a reflexionar sobre los modos en que hemos asumido que fueron estos mundos, el desafío de despegarnos en una medida de las percepciones que los agentes tuvieron de sus vidas y el modo en que otros datos o la comparación pueden aportarnos para entender como este mundo se circunscribió en una superficie social compleja.

Este elemento, sin duda, no puede reducir el sentir de los actores. El hecho de que Sebrelli (1997) describiera estas vidas como "secretas" fundando de algún modo alguna captura fantasmagórica sobre las producciones académicas posteriores. El grado de hostilidad que hemos destacado en este texto y el 
carácter ciertamente "secreto" de la identidad, en cuanto a la capacidad de los actores de valerse de este elemento como fuerza de protección, no es un hecho menor y es una característica de estas formas disidentes de presencia.

En tercer lugar, la disposición de lazos afectivos y sociales, tácticas de contención por fuera de las experiencias políticas específicas como el Frente de Liberación Homosexual resulta un elemento para medir el grado de composición comunitaria. La capacidad de extender códigos, como así también, el nivel de independencia en la elaboración de los mismos son datos que ayudan a la mensura. Lo ciertos es que estas tácticas, lejos de formar una estrategia pensada y articulada, emergieron como producto de las expectativas de supervivencia de un grupo social. Lo cual no quita su carácter social. Las prácticas conexas, que muchas veces parecen meros proyectos individuales, exhiben similitudes que permiten agruparlas en prácticas colectivas (Williams, 2012).

Este texto no quiere abandonar de ninguna manera las preocupaciones sobre las que hoy se escribe sobre el sentir de los actores, sobre las angustias y las felicidades cotidianas, sobre los meollos que de algún punto de los agentes impulsan actos, alianzas, fuerzas centrípetas y centrifugas. La pregunta por las estructuras del sentir, siempre móviles y activas, pero demarcadas y delimitadas por los desafíos de un mundo concreto, que es más material de lo que muchos parecemos discernir, plantea numerosos desafíos. Entre ellos, por ejemplo, pensar las diferencias y similitudes en perspectiva trasnacional latinoamericana o por qué no, aproximarnos a ver las divergencias internas de grupos que en nuestras narraciones, y seguro en este texto, parecen herméticas pero que no debemos subestimar, mostraban la heterogeneidad que enriquece a las ciencias sociales.

\section{Referencias bibliográficas}

AA.Vv. Perder la forma humana. España, Centro de Arte Reina Sofía, 2013. 
ACHA, O. Crónica sentimental del peronismo. Buenos Aires, Prometeo, 2014.

AchA, O; Ben, P. Amorales, patoteros, chongos y pitucos. La homosexualidad masculina durante el primer peronismo (Buenos Aires, 1943-1955). Trabajos y comunicaciones (30-31), 2004, pp.217-261.

ADAMOVSKY, E. Clase media: reflexiones sobre los (malos) usos académicos de una categoría. Nueva Sociedad, vol. 247, 2013, pp.38-49.

AltamiRano, C. Cultura de izquierda y peronismo. Buenos Aires, Siglo XXI, 2011.

BAllent, A. Las huellas de la política. Vivienda, ciudad, peronismo en buenos Aires, 1943-1955. Bernal, UNQ, 2009.

BAO, D. Invertidos Sexuales, Tortilleras, and Maricas Machos: The Construction of Homosexuality in Buenos Aires, Argentina, 19001950. Journal of homosexuality, 24(3-4), 1993, pp.183-220.

BARRANCOS, D. Problematic modernity: gender, sexuality, and reproduction in twentieth-century Argentina. Journal of Women's History, 18(2), 2006, pp.123-150.

BARRANCOS, D. Géneros y sexualidades disidentes en la Argentina: de la agencia por derechos a la legislación positiva. Cuadernos Inter.c.a.mbio sobre Centroamérica y el Caribe, vol. 11, n 2, 2014.

BAZAN, O. Historia de la homosexualidad en la Argentina. Argentina, marea, 2010.

BEN, P. Historia global y prostitución porteña: el fenómeno de la prostitución moderna en Buenos Aires, 1880-1930. Revista de Estudios Marítimos y Sociales, n 5/6, Mar del Plata, 2014.

BIERNAT, C. ¿Buenos o útiles? La política inmigratoria del peronismo, Buenos Aires, Biblos, 2007.

Bourdieu, P. La dominación masculina. Buenos Aires, Anagrama, 2013.

BRAZ, C. A. Entre sobreviventes e "bichas dos tempos dourados" tensionando geração, homossexualidade, preconceito e resistência na cidade de Goiânia. cadernos pagu 45, Campinas-SP. Núcleo de Estudos de Gênero-Pagu/Unicamp, 2015. 
cadernos pagu (49), 2017:e174914 Fronteras del deseo. Homosexualidad, sociabilidad y afecto en la ciudad de Buenos Aires (1950-1983)

BUTLER. J. Variaciones sobre sexo y género: Beauvoir, Wittig y Foucault. In: LAMAS, M. (comp.) El género. La construcción cultural de la diferencia sexual. México, Programa Universitario de Estudios de Género, 2003.

CHAUnCEY, G. Gay New York: Gender, urban culture, and the making of the gay male world, 1890-1940. Basic Books, 1994.

Cosse, I. Pareja, sexualidad y familia en los años sesenta. Buenos Aires, Siglo XXI, 2010.

D’Antonio, D. Deseo y represión. Buenos Aires, Imago Mundi, 2015.

D’EmiLIO, John. Capitalismo e identidad gay. Nuevo Topo, nº 2, Buenos Aires, 2006.

D'EmILIO, J. Sexual politics, sexual communities: The making of a homosexual minority in the United States, 1940-1970. Joseph Cady, 1983.

Eagleton, Terry. Figuras de disenso. Buenos Aires, Prometeo, 2011.

EliAS, N. El proceso de civilización. Buenos Aires, Fondo de Cultura Económico, 1994.

ERIBON, D. Reflexiones sobre la cuestión Gay. Barcelona, Anagrama, 2001.

FELITTI, Karina. En defensa de la libertad sexual: discursos y acciones de feministas y homosexuales en los '70. Temas de Mujeres, Revista del Centro de Estudios Históricos e Interdisciplinarios sobre las Mujeres (CEHIM), 2006.

FERNANDEZ, M. Perspectivas sobre la homosexualidad en la historia reciente en Argentina. Apuntes de investigación del CECYP, Año XVI, n²3, 2013, pp.153-166.

FIGARI, C. La invención de la sexualidad: el homosexual en la medicina argentina (1880-1930). In: JONES, D; FIGARI, C.; BARRÓN LOPEZ, S. La producción de la sexualidad. Políticas y regulaciones sexuales en Argentina. Buenos Aires, Biblos, 2012.

FLOYD, Kevin. The reification of desire: toward a queer Marxism. University of Minnesota Press, 2009. 
GORELIK, A. Imaginarios urbanos e imaginación urbana. Para un recorrido por los lugares comunes de los estudios culturales urbanos. bifurcaciones, 2004.

GoreliK, A. Miradas sobre Buenos Aires: historia cultural y crítica urbana. Siglo Veintiuno Editores Argentina, 2004.

INSAUSTI, S. J. Selva, plumas y desconche: Un análisis de las performances masculinas de la feminidad entre las locas del Tigre durante la década del ochenta. Revista Latinoamericana de Estudios sobre Cuerpos, Emociones y Sociedad, vol. 2, n 7, 2010, pp.29-42.

LAGUARDA, R. El ambiente: espacios de sociabilidad gay en la ciudad de México, 1968-1982. Secuencia (78), 2010, pp.149-174.

LAMAS, M. (comp.) El género. La construcción cultural de la diferencia sexual. México, Programa Universitario de Estudios de Género, 2003.

LefeBVRE, H. La producción social del espacio. Barcelona, NicholsonSmith, Donald, 1991.

Longonni, A.; Mestman, M. Del Di Tella al Tucumán Arde: vanguardia artística y política en el 68 argentino. Buenos Aires, Eudeba, 2010.

MANZANO, V. The Age of Youth in Argentina. Culture, politics and sexuality from Peron to Videla. USA, UNC Press, 2014.

MECCIA, E. Cambio y narración. Las transformaciones de la homosexualidad en Buenos Aires según los relatos de homosexuales mayores. Sexualidad, Salud y Sociedad-Revista Latinoamericana, $\mathrm{n}^{\circ}$ 19, 2015, pp.11-43.

MiRANDA, M. Controlar lo incontrolable. Una historia de la sexualidad en la Argentina. Buenos Aires, Biblos, 2011.

NESVIG, M. The Complicated Terrain of Latin American Homosexuality. Hispanic American Historical Review, vol. 81, n 3, 2001, pp.689-729.

PECHENY, M. Identidades discretas. In: ARFuCH, L. (comp.) Identidades, sujetos y subjetividades. Buenos Aires, Prometeo, 2002.

RAMACCIOTTI, K; VAlOBRA, A. El campo médico argentino y su mirada al tribadismo mirada al tribadismo, 1936-1955, 1936-1955. Revista Estudos Feministas, vol. 16, n 2, 2008, pp.493-516. 
cadernos pagu (49), 2017:e174914 Fronteras del deseo. Homosexualidad, sociabilidad y afecto en la ciudad de Buenos Aires (1950-1983)

RAPISARDI, F.; MODARELl, A. Fiestas, baños y exilios: los gays porteños en la última dictadura. Buenos Aires, Sudamericana, 2001.

Rolim, R. C.; Rodrigues, F. C. M. O assassinato de um homossexual diante de um tribunal da Capital da República em meados do século XX. Revista Estudos Feministas, 2013, pp.325-342.

SALESSI, J. Médicos maleantes y maricas: higiene, criminología y homosexualidad en la construcción de la nación argentina (Buenos Aires, 1871-1914). Beatriz Viterbo, 1995.

SCHNEIDER, A. Los compañeros. Buenos Aires, Imagomundi, 2005.

ScotT, JW. Género e historia. Buenos Aires, Fondo de Cultura Económica, 2012.

ScOTT, JW. Weapons of the weak. USA, Yale University Press, 1985.

Sebrelli, J. Historia secreta de los homosexuales en Buenos Aires. In: Escritos sobre escritos, ciudades, bajo ciudades. 1950-1997. Buenos Aires, Sudamericana, 1997.

SIDICARO, R. Los tres peronismos. Buenos Aires, Siglo XXI, 2010.

SIMONETTO, P. Mató para ser un hombre completo. Questión (44), vol. 1, 2015.

SimONETTO, P. Entre la injuria y la revolución: el Frente de Liberación Homosexual en la Argentina (1967-1976). Bernal, Editorial UNQ, 2016 (en prensa).

WiLliAmS, R. Marxismo y literatura. Buenos Aires, Las cuarenta, 2009.

WiLliAms, R. Cultura y Materialismo. Buenos Aires, La Marca editora, 2013.

ZUBIA, G. F.; LÓPEZ, A. Geografía(s) feminista(s): itinerarios y debates por las reflexiones en torno al estudio cultural de las espacialidades. Question (45), 2015.

\section{Fuentes}

\section{Prensa}

Confirmado, n60 (11-8-1966).

Somos, $n^{\circ}$ 1,2,3,4,5,6,7,8 (1971-1976). 


\section{Entrevistas}

LATRÓNICO, Nestor. Entrevista realizada personalmente 24/4/2015 y 10/12/2013.

TORRES, Sara. Entrevista realizada personalmente 12/12/2013.

Perez AlvareZ, Sergio. Entrevista realizada personalmente. 11/11/2014.

ANABITARTE Hector entrevista realizada por el Diario Clarín el 9/2/2013.

SEBRELLI, Juan José. Entrevista realizada por el Diario Página 12 27/12/2009.

\section{Mapas}

Mapas 1 y 2 elaborados en base a entrevistas y la publicación Somos.

\section{Obras literarias}

CORREA, Carlos. La narración de una historia. Buenos Aires, 1959.

Gombrowicz, W. Trans-Atlántico. Buenos Aires, Seix Barral, 2004.

Sebreli, J. J. Buenos Aires. Vida cotidiana y alienación. Buenos Aires, Siglo XX, 1964.

VILLORDO, O. La otra mejilla. Buenos Aires, Sudamericana, 1983. 